ARTICLE

\title{
Optogenetically enhanced pituitary corticotroph cell activity post-stress onset causes rapid organizing effects on behaviour
}

\author{
Rodrigo J. De Marco ${ }^{1}$, Theresa Thiemann ${ }^{1}$, Antonia H. Groneberg ${ }^{1, \dagger}$, Ulrich Herget ${ }^{1, \dagger} \&$ Soojin Ryu ${ }^{1,2}$
}

The anterior pituitary is the major link between nervous and hormonal systems, which allow the brain to generate adequate and flexible behaviour. Here, we address its role in mediating behavioural adjustments that aid in coping with acutely threatening environments. For this we combine optogenetic manipulation of pituitary corticotroph cells in larval zebrafish with newly developed assays for measuring goal-directed actions in very short timescales. Our results reveal modulatory actions of corticotroph cell activity on locomotion, avoidance behaviours and stimulus responsiveness directly after the onset of stress. Altogether, the findings uncover the significance of endocrine pituitary cells for rapidly optimizing behaviour in local antagonistic environments.

\footnotetext{
${ }^{1}$ Developmental Genetics of the Nervous System, Max Planck Institute for Medical Research, Jahnstr 29, 69120 Heidelberg, Germany. ${ }^{2}$ Focus Program Translational Neuroscience, Johannes Gutenberg University Medical Center, Langenbeckstr 1, 55131 Mainz, Germany. † Present addresses: Champalimaud Neuroscience Programme, Champalimaud Centre for the Unknown, 2 andar Avenue Brasília, Doca de Pedrouços, 1400-038 Lisbon, Portugal (A.H.G.); Division of Biology and Biological Engineering, California Institute of Technology, 1200 East California Boulevard, Pasadena, California 91125, USA (U.H.) Correspondence and requests for materials should be addressed to R.J.D.M. (email: rodrigo.de.marco@mpimf-heidelberg.mpg.de) or to S.R. (email: soojin.ryu@mpimf-heidelberg.mpg.de).
} 
$\mathrm{R}$ eversible phenotypic adaptations enable animals to adjust to local environmental changes, and usually consist of rapid physiological or sensory changes exerting meaningful influences on behaviour. Hormones govern these changes, just as the environment influences humoural responses. Antagonistic environments stimulate a range of tightly regulated processes jointly referred to as the stress response ${ }^{1}$. They serve adaptation and survival, and involve changes in physiology and behaviour on multiple timescales. The response relies heavily on the hypothalamic-pituitary-adrenal (HPA) axis, responsible for rapid and long-term processes counteracting adversity ${ }^{2}$. The pituitary gland is thus the bridge between nervous and hormonal control systems, and regulates vital functions under hypothalamic control both normally and in response to stress ${ }^{3}$.

The onset of stress elicits a modulation of anterior pituitary hormone-secreting cells through hypophysiotropic neurohormonal actions, which eventually leads to the expression and release of pituitary hormones into the circulation ${ }^{4}$. Stressors for instance prompt neurons in the paraventricular nucleus of the rostral hypothalamus to release neurotransmitters like corticotropin-releasing hormone $(\mathrm{CRH})$, the primary stimulator of the HPA axis ${ }^{5}$. CRH binds to the CRH receptor (CRHR) type 1 in pituitary corticotrophs ${ }^{6}$ and stimulates cAMP and $\mathrm{Ca}^{2}+$ increase preceding hormone secretion ${ }^{7}$. Corticotrophs comprise a fraction of the anterior pituitary and express proopiomelanocortin (POMC), the precursor of adrenocorticotropic hormone (ACTH). CRH is thus the most potent ACTH secretagogue, and stimulates corticotrophs to release ACTH which in turn induces the adrenal cortex to produce and release cortisol $^{5}$. Stress can be defined empirically as any condition eliciting the rapid release of ACTH followed by that of cortisol. Because cortisol release is consistently anchored to ACTH release, pituitary corticotrophs govern the activity of the pituitary-adrenal unit, and consequently, the long-term fate of the stress response. Immediately after the onset of stress, however, their role in regulating reversible phenotypic adaptations is far less understood.

For the stress response to be effective as an adaptive response to the environment, actions of hypothalamic and anterior pituitary neuropeptides must be temporally and spatially coordinated. How these modulators interact with each other to regulate processes within particular time windows is unclear ${ }^{8}$. Furthermore, the contribution of distinct modulators to coping behaviour has been difficult to dissect because the onset of stress affects several neurotransmitters and hormonal systems simultaneously. For instance, in addition to its endocrine functions, $\mathrm{CRH}$ may act as a neuromodulator in extrahypothalamic circuits, producing a range of autonomic, electrophysiological and behavioural effects in response to stress, including increased stimulus responsiveness 9,10 . ACTH and glucocorticoids like cortisol have central and peripheral targets, and can exert rapid actions as well. Fast glucocorticoid effects on neural activity in mammals have been documented in multiple brain areas ${ }^{11-13}$, including the hippocampus ${ }^{14,15}$, basolateral amygdala $^{16}$ and the hypothalamus ${ }^{17-19}$. Similarly, behavioural correlates of ACTH and glucocorticoid injections occurring within minutes to tens of minutes post injection have been reported $^{20-24}$. Despite these advances, the notion that pituitary corticotrophs may contribute to reversible phenotypic adaptations has so far been based on hormone injections and varying, usually delayed, measures of dissimilar end points. Due to the limited accessibility of the hypothalamus and pituitary and the coupled release of hypothalamic and pituitary neuropeptides, it has been difficult to selectively modify endogenous activity levels in pituitary corticotroph cells so as to identify their rapid modulatory actions on behaviour.
We address this question in larval zebrafish (Danio rerio) using optogenetics and find that optogenetic enhancement of corticotroph cell activity, immediately after the onset of stress, is sufficient to induce reversible phenotypic adaptations in very short timescales. Zebrafish larvae are chosen because their hypothalamic-pituitary-interrenal (HPI) axis is homologous to the HPA axis ${ }^{25}$, their genetic amenability and transparent body make them ideal for non-invasive optogenetics, and their small size allows for the continuous measurement of behaviour with full control of the environment, including the onset of acutely threatening stimuli. The activity of pituitary corticotrophs can be modified by expressing Beggiatoa photo-activated adenylyl cyclase (bPAC) ${ }^{26,27}$ specifically in these cells ${ }^{28}$. Using light of different wavelengths as both a potent stressor and a means for wavelength-dependent optogenetic control of selective cell activity, cAMP-mediated $\mathrm{Ca}^{2}+$ levels in pituitary corticotroph cells can be amplified, preceding a higher hormone release and eventually resulting in over-elevated whole-body cortisol. A set of novel assays furthermore allows the specification of the ensuing modulatory actions on locomotion, stressor avoidance and stimulus responsiveness. Altogether, our findings provide direct evidence that pituitary corticotroph cells can rapidly modulate avoidance behaviours on the onset of stress.

\section{Results}

Optogenetic manipulation of pituitary corticotroph cells. Larval zebrafish are highly sensitive to light and react to a sudden dark-to-light transition with a brief period of increased locomotion immediately after the light onset, followed by reduced locomotion during the light period and recovery of baseline locomotion after the light offset ${ }^{28}$. These locomotor reactions closely mimic those of a $\mathrm{pH}$ drop, a known potent stressor in fish (Supplementary Fig. 1a). In briefly dark-adapted larvae, a squared pulse of either blue or yellow light not only elicits locomotor reactions, but also increases whole-body cortisol in a graded manner, depending on light power (per unit of area) and exposure time (Supplementary Fig. 1b, see also ref. 28). As a result, the overall locomotion reduction occurring during the light period correlates well with light power and the ensuing cortisol level (Supplementary Fig. 1c). Considering the rapidly increased levels of cortisol as the end point of the HPI axis activation, these observations indicated that a sudden dark-to-light transition can act as a threatening stimulus that is sufficient to activate all elements of the stress response (see also Supplementary Discussion and Supplementary Movie 1). To identify rapid correlates of enhanced endocrine pituitary cell activity on stress onset, we targeted the expression of bPAC to corticotroph cells using a fragment of the POMC promoter ${ }^{29}$ (Fig. 1a, Supplementary Movie 2).

The activation of bPAC is blue-light-specific due to the protein's BLUF (blue-light receptor using flavine adenine dinucleotide)-type light sensor domain ${ }^{26,27}$. Previous work showed that the injection of bPAC mRNA into one-cell stage embryos causes a blue-light-dependent elevation of whole-body cAMP at 1 day post fertilization (d.p.f.) ${ }^{28}$. bPAC in corticotroph cells is thus expected to prompt an increased cAMP production specifically in response to blue light. In pituitary corticotrophs, cAMP increase leads to enhanced intracellular $\mathrm{Ca}^{2}+$ regulating hormone secretion $^{30}$ (see also Supplementary Discussion). We therefore monitored corticotroph cell activity in larvae expressing bPAC in pituitary corticotrophs ( $\mathrm{Tg}$ (Pomc:bPAC-2AtdTomato $)^{h d 10}$ larva $\mathrm{e}^{28}$, from now on $\mathrm{bPAC}^{+}$larvae) by targeting the $\mathrm{Ca}^{2+}$-sensitive photoprotein GFP-Aequorin ${ }^{31}$ to the same cells, thus generating double-transgenic larvae co-expressing bPAC and GFP-Aequorin ( $\mathrm{Tg}$ (Pomc:bPAC-2AtdTomato $^{\text {hd10 }}$, Pomc:GFP-Aequorin ${ }^{\text {hd20}}$ ) larvae, from now on 
a

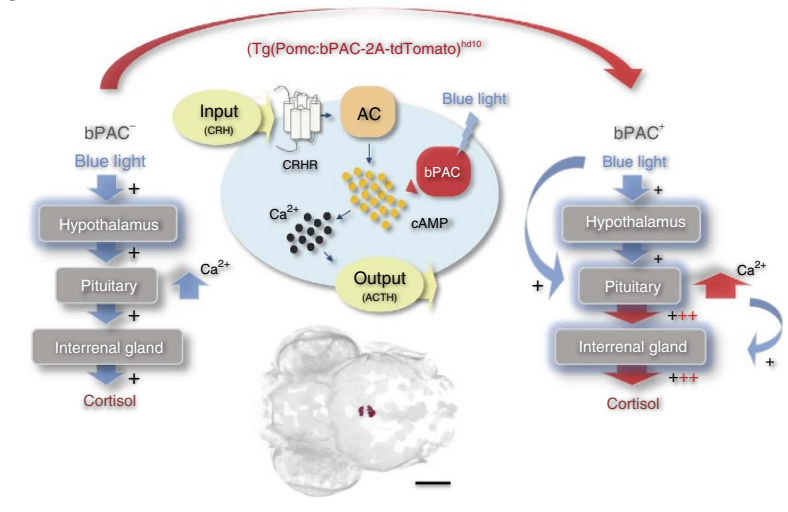

b
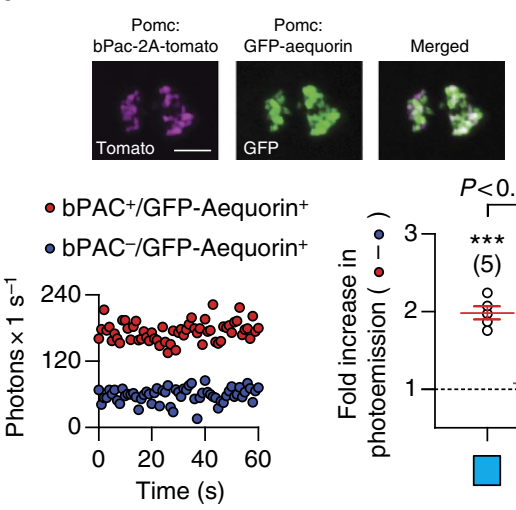

C

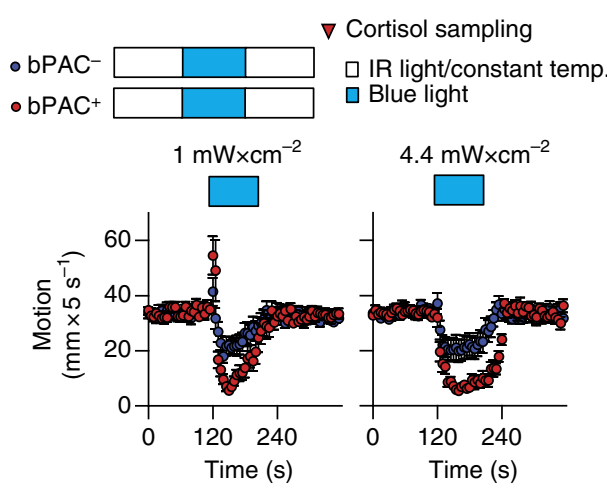

d

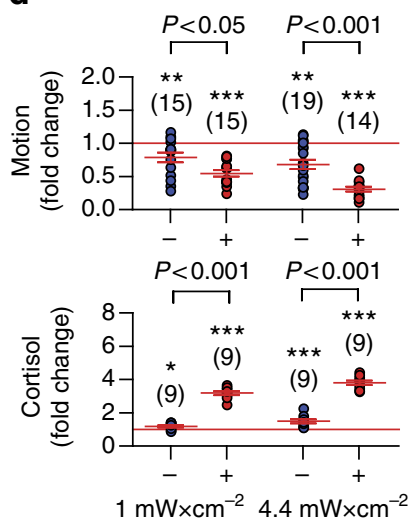

e

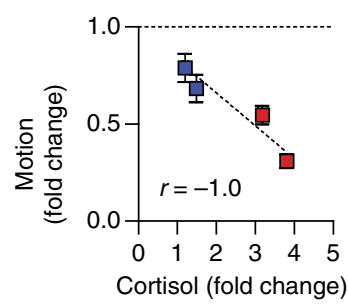

Figure 1 | Blue-light-stimulated bPAC ${ }^{+}$larvae show strengthened stress reactions. (a) Schematic showing the expected amplification of cAMPdependent hypothalamic signalling and $\mathrm{Ca}^{2}{ }^{+}$-dependent hormone release in pituitary corticotrophs in presence of bPAC. bPAC ${ }^{+}$larvae are expected to show an amplified level of pituitary corticotroph cell activity and subsequent cortisol release in response to blue light, as compared with bPAC ${ }^{-}$larvae. Bottom, dorsal view of bPAC expression in pituitary corticotrophs as detected by fused tdTomato fluorescence. Scale bar, $500 \mu \mathrm{m}$. Modified from ref. 28 . (b) The $\mathrm{Ca}^{2+}$-sensitive photoprotein GFP-Aequorin is expected to produce higher $\mathrm{Ca}^{2+}$-dependent photo-emission in corticotroph cells as a result of a blue-light-dependent bPAC activation. Top, Co-expression (right) of fluorescent tdTomato (left) and GFP (center). Scale bar, $50 \mu \mathrm{m}$. Bottom left, Representative post-blue-light $\mathrm{Ca}^{2+}$-dependent photo-emission time curves of bPAC ${ }^{+} / \mathrm{GFP}^{-A e q u o r i n}{ }^{+}$and $\mathrm{bPAC}^{-} / \mathrm{GFP}^{-A e q u o r i n}{ }^{+}$larvae preincubated in the Aequorin substrate coelenterazine, whose oxidation results in photon emission. Bottom right, After a brief exposure to blue light (blue square), bPAC ${ }^{+} /$GFP-Aequorin ${ }^{+}$larvae on average showed a twofold increase in photo-emission, that is, area under the photons s ${ }^{-1}$-time curve, as compared with bPAC $-/$ GFP-Aequorin ${ }^{+}$. This was not the case with a yellow-light exposure (yellow square), reflecting a blue-light-dependent Ca ${ }^{2+}$ increase as a blue-light-specific response ( ${ }^{\star \star \star} P<0.001$ after one-sample $t$-tests against a fold change of ' 1 ' (dashed line), $P$ value after a two-tailed $t$-test). (c) Top, groups and protocol for testing responses of briefly dark-adapted bPAC ${ }^{+}$and bPAC ${ }^{-}$larvae to a squared pulse of blue light. Bottom, individual motion (mean \pm s.e.m., in $\mathrm{mm}$ per $5 \mathrm{~s}$ ) before, during and after a squared pulse of blue light of either low (left) or high (right) power. (d) Blue-lightmediated motion (top) and cortisol (bottom) change in $\mathrm{bPAC}^{+}$and $\mathrm{bPAC}-$ larvae as a function of light power. ${ }^{\star} P<0.05,{ }^{\star \star} P<0.01,{ }^{\star \star \star} P<0.001$ after one-sample $t$-tests against a fold change of ' 1 ' (red lines), $P$ values indicate results of Bonferroni's tests after a two-way ANOVA. (b,d) Sample size in parentheses. (e) Correlation between motion and cortisol fold change from $\mathbf{c}$ and $\mathbf{d}$, respectively.

$\mathrm{bPAC}^{+} / \mathrm{GFP}^{-A e q u o r i n}{ }^{+}$larvae; Fig. 1b, top and Supplementary Movie 3). After a brief exposure to blue light, bPAC ${ }^{+} / \mathrm{GFP}_{-}$ Aequorin $^{+}$larvae on average showed a twofold increase in photo-emission as compared with their negative siblings (Tg(Pomc:bPAC-2A-tdTomato $\left.{ }^{\text {hd10 }}\right)^{-}$larvae, from now on $\mathrm{bPAC}^{-}$larvae) also co-expressing GFP-Aequorin (bPAC ${ }^{-} /$ GFP-Aequorin ${ }^{+}$larvae). This was not the case with an exposure to yellow light, further highlighting the over-elevated $\mathrm{Ca}^{2}+$ level increase as a blue-light-specific phenomenon (Fig. 1b, bottom; two-tailed $t$-test, $1 \mathrm{~mW} \mathrm{~cm}^{-2}, \mathrm{bPAC}^{+} / \mathrm{GFP}^{-A e q u o r i n}{ }^{+}$versus bPAC $^{-} /$GFP-Aequorin $^{+}, \mathrm{t}(8)=7.6, \quad P<0.0001$, one-sample $t$-test against a fold change of ' 1 ', $\mathrm{bPAC}^{+} / \mathrm{GFP}$-Aequorin ${ }^{+}$, $\mathrm{t}(4)=11.7, \quad P=0.0003$, bPAC $^{-} / \mathrm{GFP}$-Aequorin ${ }^{+}, \mathrm{t}(4)=0.9$, $P=0.42)$.

In pituitary corticotrophs, the cAMP increase downstream of CRHR activation precedes the release of $\mathrm{ACTH}^{30}$. The stimulation of bPAC by blue light, responsible for the enhanced levels of $\mathrm{Ca}^{2+}$, is thus expected to amplify the level of circulating ACTH and, as a consequence, that of whole-body cortisol (Fig. 1a) since the ACTH receptor (melanocortin receptor type 2 (MC2R)) is expressed in the interrenal gland (Supplementary Fig. 2, see also ref. 32). As expected, blue light rapidly led to a transient, wavelength-specific, light power-dependent state of over-elevated cortisol in bPAC $^{+}$larvae $^{28}$ (see also Fig. 1d). Altogether, these results indicated that, for $\mathrm{bPAC}^{+}$larvae, light can be used as a highly controllable stressor as well as a means to enhance the level of pituitary corticotroph cell output immediately after the onset of stressor exposure.

Strengthened endocrine and locomotor reactions. Following several minutes of dark-adaptation and having been subsequently exposed to a pulse of blue light, $\mathrm{bPAC}^{+}$and $\mathrm{bPAC}^{-}$larvae showed similar levels of baseline locomotion and whole-body 
cortisol before the light pulse (Supplementary Fig. 3, see also ref. 28). Both groups showed a light-mediated locomotion reduction, but the reduction was significantly greater in $\mathrm{bPAC}^{+}$larvae (Fig. 1c). Similarly, in response to light of low power, both groups showed a brief period of increased locomotion immediately after the light onset, and again a slight increase before the light offset. The magnitude of these locomotor reactions was also greater in $\mathrm{bPAC}^{+}$larvae (Fig. 1c, left). To compare light-mediated changes in locomotion between $\mathrm{bPAC}^{+}$ and $\mathrm{BPAC}^{-}$larvae, we calculated 'motion change' as the ratio between motion during and before the light pulse for each larva, with motion being measured as the integral of distance swum every $10 \mathrm{~ms}$ for equal time periods during and before the light pulse. Motion change values across groups confirmed that the higher the light power, the higher the magnitude of the light-mediated locomotion reduction, and that $\mathrm{bPAC}^{+}$larvae displayed greater reductions than $\mathrm{bPAC}^{-}$larvae (Fig. 1d, top, two-way analysis of variance (ANOVA), genotype factor: $\mathrm{F}(1,59)=24.3, \quad P<0.0001$, light power factor: $\mathrm{F}(1,59)=7.5$, $P=0.008$, genotype $\times$ light power factor: $\mathrm{F}(1,59)=1.1, P=0.30$, followed by post hoc comparisons). Similarly, so as to compare the light-mediated HPI axis activation level of $\mathrm{bPAC}^{+}$and $\mathrm{bPAC}^{-}$larvae, we calculated 'cortisol change' as the ratio between whole-body cortisol before and after $(2 \mathrm{~min})$ the light pulse for each group. Cortisol change values across groups showed that the magnitude of the light-mediated cortisol change also depended on light power: the higher the power, the higher the change, which was consistently greater in $\mathrm{bPAC}^{+}$larvae, thereby confirming previous results ${ }^{28}$ (Fig. 1d, bottom, two-way ANOVA, genotype factor: $\mathrm{F}(1,32)=317.6, \quad P<0.0001$, light power factor: $\mathrm{F}(1,32)=16.1, P=0.0003$, genotype $\times$ light power factor: $\mathrm{F}(1,32)=1.1, P=0.30$, followed by post hoc comparisons). Thus, the blue-light-mediated locomotor reduction and cortisol increase in $\mathrm{bPAC}^{+}$and $\mathrm{bPAC}^{-}$larvae were negatively correlated to each other (Fig. 1e, Spearman's rank correlation, $P<0.0001$, $r=-1.0$ ). To rule out the possibility that the observed differences in light-mediated motion and cortisol change between $\mathrm{bPAC}^{+}$and $\mathrm{bPAC}^{-}$larvae were due to non-specific effects of light on other agents of the stress response, we performed additional experiments following the same protocols but now substituting blue for yellow light, as bPAC activation is restricted to blue-light illumination ${ }^{26,27}$. Yellow light yielded effects on motion and cortisol change similar to those of blue light, but did not allow for a further group distinction between $\mathrm{bPAC}^{+}$and $\mathrm{bPAC}^{-}$larvae as it was the case with blue light (Supplementary Fig. 4). In sum, only blue light strengthened locomotor reactions and further increased whole-body cortisol in $\mathrm{bPAC}^{+}$larvae. Also, for $\mathrm{bPAC}^{+}$larvae, the magnitude of the blue-light-dependent elevation of cortisol increased with light power and exposure time. We concluded that the enhanced activity level of pituitary corticotroph cells was sufficient for inducing differences in endocrine and locomotor reactions to light between both groups of larvae.

Corticotroph cells aid in rapidly coping with threats. The lightmediated locomotor reduction occurring in wild-type and bPAC larvae in response to either blue or yellow light pointed to a regulation of locomotion that aids in coping with threatening stimuli by reducing threat exposure. To test this hypothesis, we examined a larva's choice between residing beneath filtered (darkness) and unfiltered light (Fig. 2a, insert, light power, 0 and $1 \mathrm{~mW} \mathrm{~cm}^{-2}$ for darkness and unfiltered blue light, respectively). Briefly dark-adapted (wild-type) larvae actively avoided the incidence of light when offered a choice between darkness and unfiltered light (Fig. 2a, left, frequency distribution of time intervals in light over $120 \mathrm{~s}$, right, cumulative time spent under blue light by individual larvae over a $120 \mathrm{~s}$ illumination period (in \%) relative to a maximum of $120 \mathrm{~s}$; one-sample $t$-test against $50 \%, \mathrm{t}(22)=6.2, P<0.0001)$. In bPAC siblings, this form of choice depended on bPAC expression, and the wavelength and power of the stimulating light. In response to blue light, $\mathrm{bPAC}^{-}$ larvae avoided the light irrespective of its power, as indicated by their cumulative time spent in light, and, for a high-light power, $\mathrm{bPAC}^{+}$larvae showed a greater preference for darkness. Contrary to expectations, at a low-light power $\mathrm{bPAC}^{+}$larvae did not spend more time in darkness than in light (Fig. 2b, Two-tailed $t$-test, $1 \mathrm{~mW} \mathrm{~cm}^{-2}, \mathrm{bPAC}^{+}$versus $\mathrm{bPAC}^{-}, \mathrm{t}(28)=3.1$, $P=0.005,4.4 \mathrm{~mW} \mathrm{~cm}^{-2}, \mathrm{bPAC}^{+}$versus $\mathrm{bPAC}^{-}, \mathrm{t}(26)=2.2$, $P=0.041$, one-sample $t$-test against $50 \%, 1 \mathrm{~mW} \mathrm{~cm}^{-2}, \mathrm{bPAC}^{-}$, $\mathrm{t}(15)=4.4, \quad P=0.0005, \quad \mathrm{bPAC}^{+}, \quad \mathrm{t}(13)=0.08, \quad P=0.94$, $4.4 \mathrm{~mW} \mathrm{~cm}^{-2}, \quad \mathrm{bPAC}^{-}, \mathrm{t}(12)=5.3, \quad P=0.0002, \mathrm{bPAC}^{+}$, $\mathrm{t}(14)=9.1, P<0.0001)$. However, a closer look into random samples of equal size of the low-power data indicated that $\mathrm{bPAC}^{+}$larvae not only spent overall shorter intervals in light during the $120 \mathrm{~s}$ period (Fig. 2c, Two-tailed $t$-tests, right, $\mathrm{t}(18)=4.8, P<0.0001$, left, $\mathrm{t}(18)=7.0, P<0.0001)$, indicative of a strengthened light avoidance, but also moved more frequently in the darkened half of the chamber, as indicated by the fact that they transitioned to the illuminated half much more frequently than $\mathrm{bPAC}^{-}$larvae (Fig. 2d, two-tailed $t$-test, $\mathrm{t}(18)=8.6$, $P<0.0001)$. Clearly, this enhanced locomotor activity in the darkened half of the chamber persisted during the $120 \mathrm{~s}$ period in spite of the several light exposures on the illuminated side. Since the number of dark-to-light-transitions is representative of their overall activity, these observations altogether pointed to higher stimulus responsiveness and improved coping in $\mathrm{bPAC}^{+}$larvae as compared with their negative siblings.

Without a choice between darkness and light, that is, during constant exposure to light after a brief period of dark-adaptation, both wild-type and bPAC larvae shortened their steps and increased their turns after the onset of either blue or yellow light, thus reducing their overall swum distance. Remarkably, they could also execute two distinctive behaviours. The first one was a combination of negative geotaxis and thigmotaxis (henceforth 'cloak'; Fig. 2e, top left). The second was a brief swimming burst of high speed (henceforth 'escape'; Fig. 2e, bottom left). These two behaviours appeared hierarchically organized; in so far as that the energetically less-costly cloak was more frequent than escape (Supplementary Fig. 5) and both actions could occasionally be observed alternating within a short time period. In bPAC siblings, the probability of these behaviours also depended on bPAC expression, and the wavelength and power of the stimulating light. $\mathrm{bPAC}^{+}$larvae responded to blue light of low power primarily with modified locomotion (shortened steps and increased turns), in line with the more frequent dark-to-light transitions when offered a choice between filtered and unfiltered low-power light (Fig. 2e, centre, G-test, $P=0.003$ ). As a result, they on average showed less cloaks and escapes than bPAC $^{-}$ larvae. By contrast, in response to blue light of higher power, $\mathrm{bPAC}^{+}$larvae displayed more frequent and lengthy escapes than bPAC $^{-}$larvae (Fig. 2e, right, G-test, $P=0.0004$, Fig. 2f, two-tailed $t$-test, $\mathrm{bPAC}^{+}$versus $\mathrm{bPAC}^{-}, \mathrm{t}(15)=3.5, P=0.004$; Supplementary Movies 4 and 5), in line with a greater preference for darkness (less time spent in light) when offered a choice between filtered and unfiltered light of high power. Yellow light did not yield a similar distinction between bPAC siblings (Supplementary Fig. 6). Both $\mathrm{bPAC}^{+}$and $\mathrm{bPAC}^{-}$responded in the same manner (as the bPAC $^{-}$with blue light), with a preference for darkness when offered a choice, irrespective of light power and bPAC expression (Supplementary Fig. 6a). Similarly, for light of low and higher power, both groups showed 
a

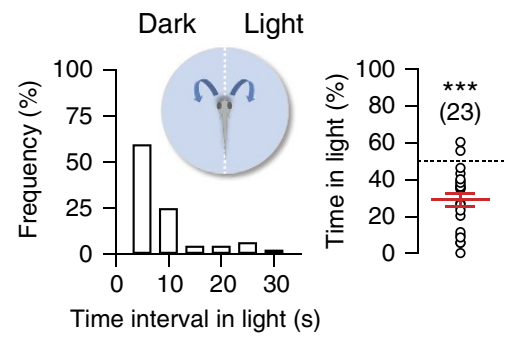

b

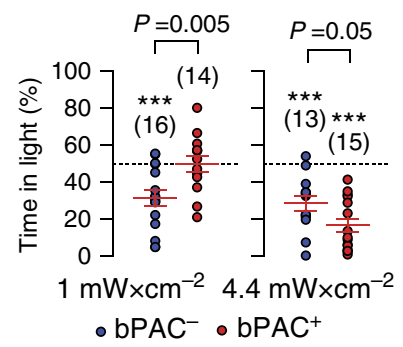

c

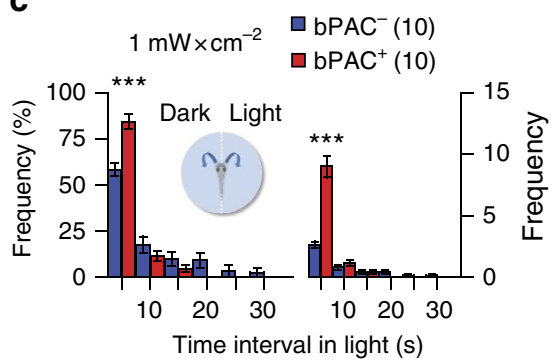

d

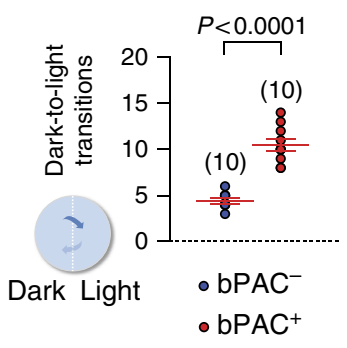

e

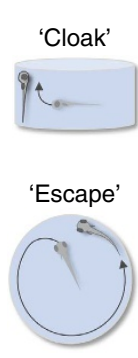

$\square \mathrm{bPAC}$

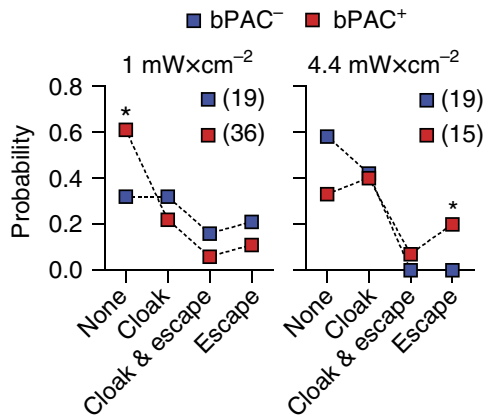

f

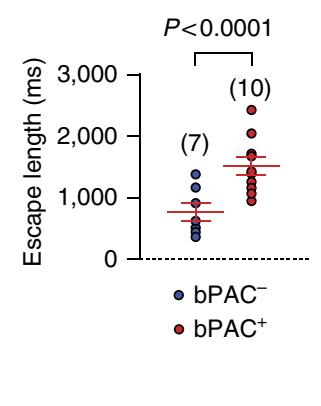

Figure 2 | Enhanced pituitary corticotroph cell activity causes rapid adjustments of stressor avoidance. (a) Inset, configuration for assessing light avoidance in freely swimming larvae. Left, distribution of time intervals under unfiltered light during a $120 \mathrm{~s}$ period of blue-light illumination. Right, cumulative time spent under blue light by individual wild-type larvae over a 120 s illumination period (in \%) relative to a maximum of 120 s. (b) Cumulative time spent under blue light (as in a) by individual bPAC ${ }^{+}$and bPAC - larvae for two different light powers; $P$ values show results after two-tailed $t$-tests. $(\mathbf{a}, \mathbf{b}){ }^{\star \star \star} P<0.001$ after one-sample $t$-tests against $50 \%$. (c) Inset, configuration for assessing light avoidance in freely swimming larvae (as in a). Light power, $1 \mathrm{~mW} \mathrm{~cm}^{-2}$. Relative (in \%) (left) and absolute (right) frequencies of time intervals under unfiltered light (mean \pm s.e.m.) by individual bPAC + and bPAC - larvae during a $120 \mathrm{~s}$ period of blue-light illumination. ${ }^{\star \star \star} P<0.001$ after Two-tailed $t$-tests. (d), Total number of dark-to-light transitions by individual $\mathrm{bPAC}^{+}$(red) and $\mathrm{bPAC}^{-}$(blue) larvae during the $120 \mathrm{~s}$ period of blue-light illumination ( $P$ value after a Two-tailed $t$-test). (e), Left, Scheme showing avoidance behaviours elicited by continuous light exposure: 'cloak' (top), negative geotaxis combined with thigmotaxis and 'escape' (bottom), a swimming burst. Right, probabilities of responses to blue light in $\mathrm{bPAC}^{+}$and $\mathrm{bPAC}^{-}$larvae as a function of light power. ${ }^{\star} \mathrm{P}<0.05$ after $\mathrm{G}$-tests. (f) Length of escape reactions by individual $\mathrm{bPAC}^{+}$and $\mathrm{bPAC}^{-}$larvae during blue-light stimulation. Light power, 1 and $4.4 \mathrm{~mW} \mathrm{~cm}^{-2} . P$ value after a two-tailed $t$-test. (a-f) Sample size in parentheses.

no difference concerning the frequency of cloaks and escapes, as well as escape length (Supplementary Fig. 6b,c).

On the underlying assumption that a larva's goal of reducing the incidence of light is mediated by stimulus salience and strength on the one side, and their capacity for threat detection and mobilizing resources on the other, $\mathrm{bPAC}^{+}$larvae appeared to be better equipped to handle a threatening environment by first seeking avoidance of the threat cue altogether, and if not given a choice, by directly investing more resources into elaborate cloaks and escapes. Thus, $\mathrm{bPAC}^{+}$larvae showed an affinity towards modified locomotor patterns at a low-light power, and cloak and escape responses at a high-light power, coupled with greater avoidance if given a choice. Cloak and escape presumably require more resources to actively sustain, making these responses more demanding. For low-light powers, bPAC activation might better prepare larvae to tolerate low-level threats, whereas at a high-light power they will still be able to allocate a vaster capacity towards the potentially more efficient escape.

Increased stimulus responsiveness under stress. To test if stressor exposure leads to increased stimulus responsiveness in larval zebrafish, we developed two novel behavioural assays with a focus on measuring responsiveness to different sensory stimuli, and assessments of both avoidance and attraction. In addition, to better pinpoint effects invariant to stressor identity, we used three different stimulations eliciting avoidance reactions and cortisol increase in a stimulus intensity-dependent manner: exposure to either light, hyperosmotic medium or strong hydrodynamic flows (Fig. 3a, see also refs 28,33). To compare the level of HPI axis activation produced by these stimulations, we first measured whole-body cortisol in wild-type larvae directly after stressor exposure. Cortisol values across groups of pre-exposed (stressed) larvae had nearly equal distributions and were, on average, $\sim 230 \%$ higher than those of unexposed larvae (Fig. 3b, one-way ANOVA, $\mathrm{F}(4,54)=16.4, \quad P<0.0001$, followed by post hoc comparisons, One-sample $t$-test against basal cortisol, yellow light: $\mathrm{t}(10)=8.0, P<0.0001$, blue light: $\mathrm{t}(10)=8.5, P<0.0001$, NaCl: $\mathrm{t}(10)=8.6, P<0.0001$, strong flows: $\mathrm{t}(10)=7.9, P<0.0001)$.

Next, in the first assay, we determined the link between stressor exposure and the subsequent reaction of a freely swimming larva encountering a higher surrounding water temperature. We monitored the movements of single larvae swimming in darkness in a small, cylindrical chamber with an opposing in and outlet before and after a sharp temperature increase of the flowing medium, which, owing to the layout of the chamber and heat conduction, led to a significant temperature difference between the inlet (high temperature, zone 1) and outlet (low temperature, zone 2) area (Fig. 3c, see also Supplementary Fig. $7 c$ and see the 'Methods' section). After the onset of temperature rise, larvae entering the high-temperature area reacted to an increasing surrounding temperature with fast turns and greater swim velocity (Fig. 3d). To quantify their overall response, we measured 'differential speed' $(\Delta S)$ as the difference (in \%) between the swim velocity $\left(\mathrm{mm} \times(40 \mathrm{~ms})^{-1}\right)$ in zone 1 and 2 for each larva, or 
a

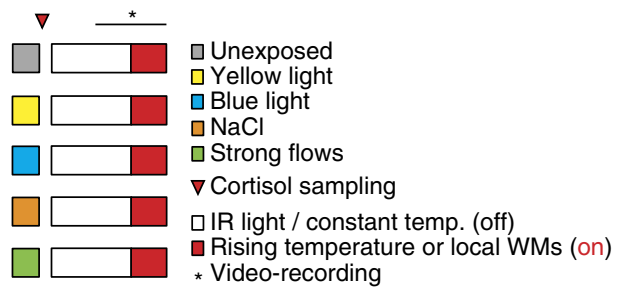

d
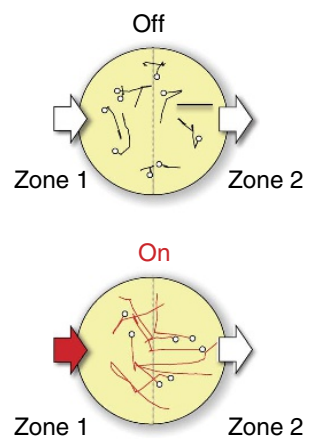

b

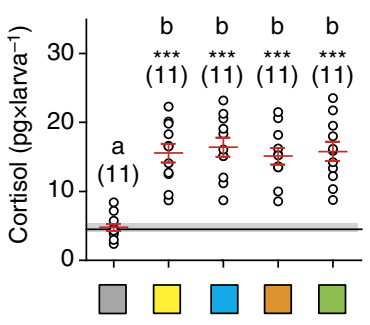

f

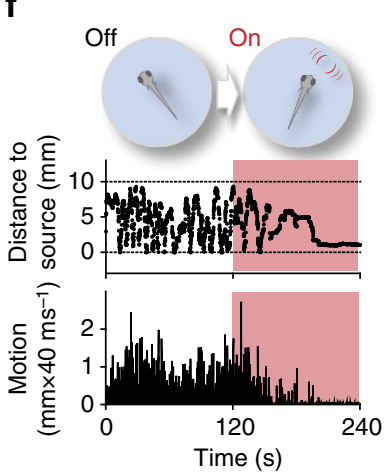

c

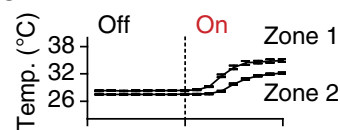

( Zone 1 - Zone 2 )

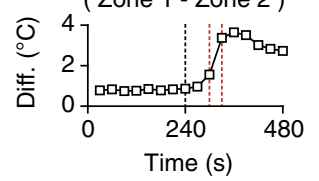

g

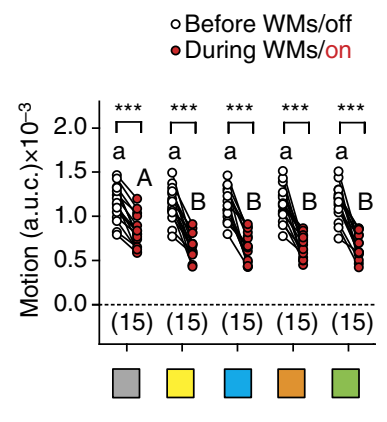

Figure 3 | Increased stimulus responsiveness follows stressor exposure in wild-type larvae. (a) Groups for testing the effect of stressor exposure on larval responsiveness to rising temperature and WMs. (b) Whole-body cortisol in wild-type larvae for the groups in a. Letters indicate results from post hoc tests after a one-way ANOVA $(P<0.01)$ and asterisks $(P<0.001)$ from one-sample $t$-tests against basal cortisol in controls (black line). (c) Increasing the temperature of the flowing medium raises the temperature difference $(\Delta \mathrm{T})$ between the opposing inlet (higher temperature, zone 1) and outlet (lower temperature, zone 2) of the swimming chamber. Top, mean temperature ( \pm s.e.m.) in zones 1 and 2 as a function of time. Bottom, $\Delta T$ as a function of time. (d) From top to bottom, representative $1 \mathrm{~s}$ swim paths from pre-exposed larvae showing increased speed and turns near zone 1 as $\Delta T$ increases. White dots indicate start positions. Scale bar, $2.5 \mathrm{~mm}$. (e) Differential speed (the difference between swim velocity (mm per $40 \mathrm{~ms}$ ) in zone 1 and 2 (in \%)) for the groups in a before and after the onset of temperature rise. (f) Schematic showing the stimulation procedure (top) and representative traces of a larva's distance to stimulus source (middle) and swim velocity (bottom) before and after the onset of WMs. Red backgrounds depict the period of WMs.

(g) Motion level, that is, area under the swim velocity-time curve over $120 \mathrm{~s}$, in wild-type larvae before and during WMs. (e,g) Letters and asterisks indicate results from post hoc comparisons after a two-way repeated measures ANOVA $(P<0.001)$. (b,e,g) Sample size in parentheses.

((swim velocity in zone 1 -swim velocity in zone 2$) /$ swim velocity in zone 2$) \times 100$, before $(30 \mathrm{~s})$ and after (60-90s) the onset of the temperature rise (see also the 'Methods' section). The distribution of $\Delta S$ values across groups revealed that unexposed larvae displayed only slightly modified locomotion patterns in zones 1 and 2 after the onset of temperature rise, whereas larvae pre-exposed to stressors had nearly equally distributed $\Delta \mathrm{S}$ values that were, on average, $316 \%$ higher than those of unexposed larvae (Fig. 3e, top, two-way repeated measures ANOVA, time factor: $\mathrm{F}(1,60)=246.2, P<0.0001$, treatment factor: $\mathrm{F}(4,60)=5.6$, $P=0.0006$, time $\times$ treatment factor: $\mathrm{F}(4,60)=7.0, P=0.0001$, followed by post hoc comparisons).

In the second assay, we applied subtle hydrodynamic stimuli to similar groups of wild-type larvae (Fig. 3a). Hydrodynamic sensing provides fish with various benefits, ranging from object detection to sensing conspecifics ${ }^{34}$. Larval zebrafish, for instance, respond to local, non-stressful water motions (WMs) with positive taxis and reduced locomotion ${ }^{35}$. The onset of WMs first leads them to approach the stimulus source and reduce their locomotion gradually; they then remain virtually immobile in the proximity of the source as long as WMs persist (Fig. 3f). This response is highly sensitive to stimulus frequency and strength, sensory background and rearing conditions ${ }^{35}$, and offers an excellent handle for assessing subtle changes in stimulus responsiveness. To quantify a larva's response to WMs, we focused on the WM-induced locomotion reduction and measured integrals of distance swum every $40 \mathrm{~ms}$ for equal periods before and during WMs for each larva (see the 'Methods' section).
The distribution of motion values across groups showed responses for pre-exposed larvae that were, on average, $20 \%$ greater than those of unexposed larvae, consistent with the idea that increased stimulus responsiveness follows stressor exposure (Fig. 3g, two-way repeated measures ANOVA, time factor: $\mathrm{F}(1,70)=402.9, \quad P<0.0001$, treatment factor: $\mathrm{F}(4,70)=1.0$, $P=0.41$, time $\times$ treatment factor: $\mathrm{F}(4,70)=2.2, \quad P=0.08$, followed by post hoc comparisons). Taken together, these results indicated that the various stressors produced positively correlated changes in cortisol, $\Delta S$ and motion values.

Using bPAC siblings, we then tested if bPAC activation in corticotroph cells influences stressor-mediated levels of stimulus responsiveness. To test this possibility, we determined whether $\mathrm{bPAC}^{+}$and $\mathrm{bPAC}^{-}$larvae pre-exposed to either blue or yellow light were equally reactive to increasing water temperature and WMs (Fig. 4a). As expected, both blue and yellow light increased whole-body cortisol in $\mathrm{bPAC}^{+}$and $\mathrm{bPAC}^{-}$larvae, and the resulting levels were significantly higher (42\%) in $\mathrm{bPAC}^{+}$larvae only after blue-light exposure (Fig. 4b, two-way ANOVA, genotype factor: $\mathrm{F}(1,54)=7.5, P=0.008$, treatment factor: $\mathrm{F}(2,54)=91.9, P<0.0001$, genotype $\times$ treatment factor: $\mathrm{F}(2,54)=5.3, P=0.008$, followed by post hoc comparisons). Notably, $\Delta S$ and motion values showed (a) that unexposed $\mathrm{bPAC}^{+}$and $\mathrm{bPAC}^{-}$larvae responded similarly to increasing surrounding water temperature and WMs, (b) that blue and yellow light increased their responses as in wild-type larvae and (c) that $\mathrm{bPAC}^{+}$larvae had much greater responses than $\mathrm{bPAC}^{-}$ larvae only after blue-light exposure (Fig. 4c,d, two-way repeated 
a

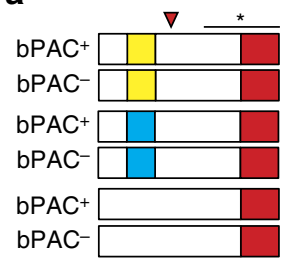

$\square$ IR light/constant temp.

$\square$ Yellow light / $\square$ Blue light

$\nabla$ Cortisol sampling

$\square$ Rising temperature or local WMs

* Video-recording

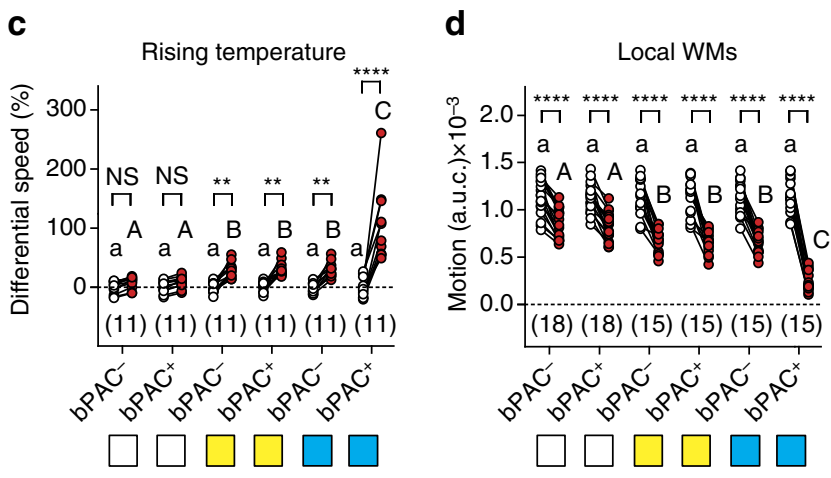

Figure 4 | bPAC activation is sufficient to further elevate the level of stressor-mediated stimulus responsiveness. (a) Groups for testing the response of $\mathrm{bPAC}^{+}$and $\mathrm{bPAC}^{-}$larvae to rising temperature and WMs. (b-d) Whole-body cortisol, differential speed and motion level (as in Fig. 3b, $(\mathbf{e}, \mathbf{g})$ respectively) for the groups in a. Asterisks $\left({ }^{\star \star \star} P<0.001\right.$, $\left.{ }^{\star \star \star \star} * P<0.0001\right)$ and lower- and upper-case letters $(P<0.001)$ indicate results from Bonferroni's tests after a two-way ANOVA (b) and two-way repeated measures ANOVAs (c,d). Sample size in parentheses.

measures ANOVA, $\Delta \mathrm{S}$, time factor: $\mathrm{F}(1,60)=117.9, P<0.0001$, group factor: $\mathrm{F}(5,60)=11.6, P<0.0001$, time $\times$ group factor: $\mathrm{F}(5,60)=19.9, \quad P<0.0001, \quad$ motion values, time factor: $\mathrm{F}(1,90)=747.1, \quad P<0.0001, \quad$ group factor: $\mathrm{F}(5,90)=9.6$, $P<0.0001$, time $\times$ group factor: $\mathrm{F}(5,90)=25.2, \quad P<0.0001$, followed by post hoc comparisons). These results indicated that bPAC activation post-stress onset was sufficient to further elevate the level of stimulus responsiveness.

\section{Discussion}

The difficult in vivo accessibility of the hypothalamus and pituitary gland, and the rapid and synchronous release of stress-sensitive modulators have made it difficult to determine the contribution of distinct HPA-axis effectors on immediate reactions to stress. Zebrafish offer a highly in vivo accessible and easy-to-handle model for HPA signalling at the same time as a high physiological and neuroanatomical homology to mammals. The zebrafish HPI axis shares conspicuous homologies with the HPA axis in humans ${ }^{25}$ and the larval neurosecretory preoptic-hypothalamic area is also homologous to the hypothalamic paraventricular nucleus in mammals ${ }^{36}$. Notably, the HPI axis matures very early in development from 4 d.p.f. onwards $^{37-39}$ and its principal cell clusters can be visualized and manipulated using genetic tools (Supplementary Movie 1). Furthermore, as in mammals, stressors induce predictable alterations in the locomotor activity and feeding drive of freely behaving larvae ${ }^{28,33}$ (see also Supplementary Discussion). Our findings uncover fast organizing effects of pituitary corticotroph cells on behaviour, providing direct evidence that rapid behavioural adjustments on stressor exposure can occur depending on the activity level of pituitary corticotrophs. The results are consistent with literature pointing to joint actions of brain neuropeptides and peripheral hormones ${ }^{8}$ and suggest that a higher level of endocrine pituitary cell activity post onset of stress can yield an advantage in coping with acutely threatening environments.

Although CRH has been shown to elicit rapid behavioural effects ${ }^{10}$, its involvement alone does not account for the differences between $\mathrm{bPAC}^{+}$and $\mathrm{bPAC}^{-}$larvae in the range of responses examined here. Experiments using the same protocols but with yellow light failed to produce the same group differences as blue light yielded for the wavelength-specific activation of bPAC in $\mathrm{bPAC}^{+}$larvae. This failure further dissociates general effects of light as a stressor from those specific to bPAC activation, namely enhanced cAMP-mediated $\mathrm{Ca}^{2+}$ levels in corticotroph cells preceding a higher level of corticotroph output and eventually resulting in higher whole-body cortisol. Without the bPAC-mediated corticotroph output modification, endocrine and behavioural end points showed similar values between groups for yellow light. Light as a stressor thus fails to account for a distinction between $\mathrm{bPAC}^{+}$and $\mathrm{bPAC}^{-}$larvae.

Significant differences between both groups emerged with blue light, in line with the idea that the group differences did not result from the initial activity level of the hypothalamic-pituitary unit, but from downstream processes. We had shown in bPAC ${ }^{+}$ larvae that blue light can be used as both a potent stressor and a means to enhance pituitary corticotroph cell activity, thus prompting a higher cortisol level ${ }^{28}$. The fact that light in this dual role can be accurately controlled is important in understanding how distinct stress modulators influence behaviour immediately after the onset of stress, since the combined effects of HPA-axis effectors can occur at short timescales. Compared with controls, $\mathrm{bPAC}^{+}$larvae showed locomotion changes occurring just seconds after the light onset, and a few seconds later they also showed adjustments in avoidance behaviours, followed by greater stimulus responsiveness after the light offset; clearly, the speed of these effects speaks against innocuous effects of the amplified corticotroph cell activity.

Studies in mammals showed that injections of ACTH and related peptides can alter forms of avoidance ${ }^{20,40,41}$, stretching and yawning ${ }^{42}$, grooming ${ }^{43}$ and sexually motivated actions ${ }^{44}$; thus a role for pituitary peptides in regulating arousal has been suggested ${ }^{45}$. Evidence also shows that glucocorticoid administration can influence locomotion ${ }^{22,46}$, agonistic reactions ${ }^{47-49}$ and courtship ${ }^{23,50,51}$. These studies relied on injections of exogenous hormones and behavioural measures of varying delays; rapid effects of endogenous effectors from the pituitary-adrenal unit have not been documented before. The change in $\mathrm{Ca}^{2+}$-dependent photo-emission and whole-body cortisol gave direct evidence that light activated the HPI axis of the zebrafish larva, prompting the rapid release of corticotroph and steroidogenic interrenal cell products. Our findings thus agree with previous studies and extend those for the first time towards rapid effects of endogenous corticotroph cell products on behaviour.

The blue-light-dependent behavioural adjustments in $\mathrm{bPAC}^{+}$ larvae may set in once the activity of either corticotroph or interrenal cells, or both, is enhanced. Active molecules have been ascribed to both cell types. Corticotrophs produce several active peptides resulting from the cleavage and processing of the precursor gene POMC, like ACTH, pro- $\gamma$-melanocytestimulating-hormone (MSH) and $\beta$-lipotrophin (LPH). $\beta$-LPH is further cleaved to $\beta$-endorphin and a proportion of ACTH can be cleaved to $\alpha-\mathrm{MSH}$ and corticotrophin-like intermediate peptide ${ }^{52}$. These POMC-derived peptides can lead to behavioural change 
when injected into rats, and ACTH fragments like ACTH 1-10 and ACTH 4-10, also present in $\alpha-\mathrm{MSH}, \beta-\mathrm{MSH}$ and $\beta-\mathrm{LPH}$, have similar effects on avoidance as ACTH itself ${ }^{21}$. Moreover, ACTH fragments devoid of adrenal function can prompt behavioural changes as well, suggestive of a central role for pituitary-derived peptides that may be transported back to the brain $^{53}$, although central mechanisms underlying rapid effects of pituitary peptides on behaviour have not yet been reported.

In fish, behavioural effects of POMC-derived peptides have been studied primarily in the context of food intake and pigmentation ${ }^{54}$, but not in that of stress. ACTH stimulates the release of steroids from the adrenal cortex via the MC2R. Evidence indicates that the expression of MC2R is restricted to the adrenal cortex, although conflicting results have been reported concerning the role of ACTH in the release of epinephrine and norepinephrine by cells in the adrenal medulla 55,56 . The interrenal gland of teleosts does not have a strict separation between cortex and medulla. In larval zebrafish, steroidogenic and catecholaminergic cells are intermingled, and MC2R expression is restricted to steroidogenic cells (Supplementary Fig. 2). In mammals, the adrenal cortex produces glucocorticoids, mineralocorticoids and androgens. In teleosts, steroidogenic cells produce mainly cortisol, responsible for glucocorticoid and mineralocorticoid actions. Ultradian and circadian $^{57,58}$ as well as stress-induced glucocorticoid variations have wide-reaching cellular correlates. Glucocorticoid actions in a number of brain regions involve membrane-bound and nuclear forms of mineralocorticoid and glucocorticoid receptors, as well as a yet unidentified G-protein-coupled receptor (reviewed in refs 59,60). Despite these advances, how glucocorticoids, and hypothalamic and anterior pituitary neuropeptides interact with each other to activate and inactivate stress-sensitive processes across multiple time windows still remains unclear.

In this study, we uncovered reversible phenotypic adaptations attributable to enhanced corticotroph cell activity immediately after the onset of stress. In addition, we added a series of robust assays to a growing repertoire of laboratory tests in larval zebrafish. Genetic tools to modify hypothalamic, corticotroph and steroidogenic cell function are being developed ${ }^{28,61,62}$ and can be combined with optogenetics, pharmacology and behavioural screens to specify distinct actions of HPA-axis hormones and downstream effectors.

\section{Methods}

Zebrafish husbandry and handling. Zebrafish breeding and maintenance were performed under standard conditions ${ }^{63}$. Embryos were collected in the morning and raised on a 12:12 light/dark cycle in E2 medium (wild-type and bPAC larvae), or in E3 medium with $0.2 \mathrm{mM}$ N-phenylthiourea (PTU, Sigma-Aldrich, \#P7629; GFP-Aequorin larvae), at $28^{\circ} \mathrm{C}$. To avoid unspecific activation of bPAC before the tests, transgenic and control embryos were raised inside custom-made reflective containers covered with $550 \mathrm{~nm}$ long-pass filters (Thorlabs, Dachau, Germany; Supplementary Fig. 3a). All experiments were carried out with wild-type or transgenic larvae at 4-6 d.p.f. Tests were performed between 09:00 hours and 18:00 hours, with different experimental groups intermixed throughout the day. Zebrafish experimental procedures were performed according to the guidelines of the German animal welfare law and approved by the local government (Regierungspräsidium Karlsruhe; G-29/12).

Transgenic lines. $T g$ (Pomc:bPAC-2A-tdTomato $)^{h d 10}$ fish (bPAC) ${ }^{28}$ were crossed with wild-type fish (cross of $\mathrm{AB}$ and $\mathrm{TL}$ strains, $\mathrm{AB} / \mathrm{TL}$ ) and their progenies maintained in E2 medium and screened (without anaesthetics) for pituitaryspecific tdTomato expression $\left(\mathrm{bPAC}^{+}\right)$, or its absence $\left(\mathrm{bPAC}^{-}\right)$, at $3-5$ d.p.f., at least 1 day before behavioural or cortisol tests. All screenings were performed using a Leica MZ6 fluorescence microscope. To generate the pomc:GFP-Aequorin construct, an $\sim 1 \mathrm{~kb}$ DNA region, upstream of the start codon of the zebrafish pomc gene ${ }^{29}$ was PCR-amplified using the forward primer $5^{\prime}$-GGATTAATCTG CTTTAAGACCTCAATTTTTGAGAC- $3^{\prime}$ and the reverse primer $5^{\prime}$-AAAGCTAG CCACTCCCCTCACCATCTCTGAGA-3' ${ }^{\prime}$. The forward primer included an Ase 1 restriction site while the reverse primer included a Nhel-restriction site. The amplified pomc promoter fragment was used to replace the CMV promoter of the
pG5A vector ${ }^{31}$, which contains Aequorin fused in frame at the $3^{\prime}$-end of the EGFP with a 5 amino acid linker between GFP and apoaequorin. The recombinant plasmid was injected into one-cell stage $\mathrm{AB} / \mathrm{TL}$ wild-type embryos at $10 \mathrm{ng} \mu \mathrm{l}^{-1}$ concentration in the presence of $10 \mathrm{ng} \mu \mathrm{l}^{-1} \mathrm{Tol} 2$ transposase mRNA and $0.05 \%$ phenol red (Sigma-Aldrich, \#P3532). The progenies of injected fish were maintained in egg water supplemented with $0.2 \mathrm{mM}$ PTU to prevent pigmentation and screened for pituitary-specific GFP expression at 2-4 d.p.f. A single G0 founder was used to establish a stable F1 family for $\operatorname{Tg}(\text { Pomc:GFP-Aequorin })^{h d 20}$. $\mathrm{Tg}$ (Pomc:bPAC-2A-tdTomato $)^{\text {hd } 10}$ and $\mathrm{Tg}$ (Pomc:GFP-Aequorin $)^{\text {hd } 20}$ fish were crossed and raised in E3 medium plus $0.2 \mathrm{mM}$ PTU and screened for pituitaryspecific co-expression of tdTomato and GFP (bPAC ${ }^{+} / \mathrm{GFP}^{-A e q u o r i n}{ }^{+}$) or single expression of GFP (bPAC ${ }^{-} / \mathrm{GFP}^{-A e q u o r i n}{ }^{+}$) at 3 d.p.f.

Staining and microscopy. Riboprobes for the steroidogenic acute regulatory pro tein (star) ${ }^{64}$ and $m c 2 r$ were synthesized from linearized plasmids following instructions provided with the digoxygenin-labelling mix (Roche, \#11277073910) Whole-mount fluorescent in situ hybridization and immunohistochemistry were performed as described elsewhere ${ }^{65,66}$, using a primary rabbit antibody labelling tyrosine hydroxylase ${ }^{67}(1: 250)$ and the secondary anti-rabbit antibody Alexa 647 (Invitrogen, \#A-21245, 1:1,000). For imaging, specimens were cleared in $80 \%$ glycerol (Gerbu, \#2006) in phosphate-buffered saline for $1 \mathrm{~h}$. Confocal stacks were recorded using a Leica SP5 confocal microscope with a Nikon $20 \times$ glycerol objective. In vivo images of cell populations forming the three elements of the HPI axis were recorded using specific transgenic expression in stable lines and in situ cell type mapping. Transgenic larvae expressing OtpECR6:RFPcaax ${ }^{61}$, pomc:GFP 29 and StAR:GFP 62 were embedded in $1 \%$ low-melt agar (Roth, \#6351) and imaged in vivo using a Leica SP 5 confocal microscope with a $20 \times$ water objective (see also Supplementary Methods). Stacks were evaluated using Amira 5.4 (FEI

Visualization Sciences Group) to create maximum intensity projections and rotation videos, and spatially restricted to the volume of interest, excluding signals from planes in front or behind. Brightness and contrast were adjusted for each channel.

Setup. Video recordings using blue and yellow light, hydrochloric acid $(\mathrm{HCl}$, Merck, \#109063), rising temperature and non-stressful WMs were made under infrared illumination delivered through a custom-made array of infrared-LEDs mounted inside a light-proof enclosure. Custom-made drivers, amplifiers, pulse generators and a TTL control box (USB-IO box, Noldus Information Technology, Wageningen, The Netherlands) allowed computer control of blue- and yellow-light illumination, pH level and mechanosensory stimuli (Supplementary Fig. 7a). Larvae were imaged through infrared-sensitive cameras, at either 25 (ICD-49E B/W, Ikegami Tsushinki Co, Ltd, Japan) or 100 frames s $^{-1}$ (Firewire Camera, Noldus Information Technology), with a lens (TV Lens, Computer VARI FOCAL H3Z4512 CS-IR, CBC; Commak, NY, USA) positioned above a cylindrical custommade swimming chamber (Supplementary Fig. 7b). The complete setup was placed on a vibration-free platform (Newport Corp, Irvine, CA, USA). EthoVision XT 7 software (Noldus Information Technology) was used to monitor the movements of individually swimming larvae. Motion values from video recordings made at 25 and 100 frames s$^{-1}$ were expressed as distance swum every $40(\mathrm{~mm}$ per $40 \mathrm{~ms})$ and $10 \mathrm{~ms}$ (mm per $10 \mathrm{~ms}$ ), respectively. The swimming chamber (internal diameter: $10 \mathrm{~mm}$, height: $10 \mathrm{~mm}$ ) had a transparent bottom and two opposite overtures, inlet and outlet (width: $2.5 \mathrm{~mm}$, height: $400 \mu \mathrm{m}$; Supplementary Fig. $7 \mathrm{c}$, top), allowing medium (E2 or E3) to constantly flow at $200 \mu \mathrm{min}^{-1}$ by means of a peristaltic pump (IPC Ismatec, IDEX Health and Science GmbH, Wertheim, Germany). The chamber also had two cylindrical side channels (internal diameter: $400 \mu \mathrm{m}$ ) opposite to each other opening $200 \mu \mathrm{m}$ above the transparent glass bottom, with their longest axis oriented at an angle of $30^{\circ}$ relative to horizontal (Supplementary Fig. 7c, bottom). One such channel held a thermocouple (TS200, npi electronics $\mathrm{GmbH}$, Tamm, Germany) monitoring the temperature inside the chamber and providing feedback to a control system (PTC 20, npi electronics GmbH; Exos-2 V2 liquid cooling system, Koolance, Auburn, WA, USA) that either kept the flowing medium at $28^{\circ} \mathrm{C}\left( \pm 0.1^{\circ} \mathrm{C}\right)$ or increased its temperature rapidly in a highly controlled manner (see below). The second side channel allowed passage of the end of a rigid silica capillary tube, or stimulus source (outer diameter: $350 \mu \mathrm{m}$, full length: $25 \mathrm{~mm}$, Polymicro Technologies), submerged $\sim 400 \mu \mathrm{m}$ into the chamber's inner medium (depth: $5 \mathrm{~mm}$ ). The opposite end of the capillary tube was fixed to a multilayer bender actuator (PICMA PL140.10, Physik Instrumente (PI) $\mathrm{GmbH}+\mathrm{Co} . \mathrm{KG}$, Karlsruhe, Germany) with an operating voltage of 0-60 V, a maximum displacement of $\pm 1,000 \mu \mathrm{m}$ and an unloaded resonant frequency of $160 \mathrm{~Hz}$. The bender, coupled to a pulse generator, a dual piezo amplifier and a TTL control system, produced unidirectional lateral displacements (of $50 \mu \mathrm{m}$ and controllable speed) of the capillary's submerged end, creating minute, non-stressful WMs within the chamber. The input voltage applied to the actuator $(0.5 \mathrm{~V})$ determined the speed of the capillary's lateral displacements ${ }^{35}$. To monitor a larva's response to a $\mathrm{pH}$ drop, a computer-controlled perfusion system (Octaflow, ALA Scientific Instruments, Inc, Farmingdale, NY, USA) injected $2 \mu \mathrm{l}$ of $\mathrm{HCl}$ solution $(250 \mathrm{mM})$ into a cylindrical mixing compartment (internal diameter: $1 \mathrm{~mm}$ ) situated $10 \mathrm{~mm}$ from the inlet of the swimming chamber. The mixing compartment was connected to a reservoir of $\mathrm{HCl}$ solution coupled to a computer-controlled solenoid valve via Teflon tubing (internal diameter: $230 \mu \mathrm{m}$, outer diameter: 
$600 \mu \mathrm{m}$ ). TTL signals triggered the opening and closing of the valve (time: $1 \mathrm{~s}$, pressure: 1 p.s.i.), allowing the $\mathrm{HCl}$ solution to be well mixed with the flowing medium before reaching the inner chamber. For blue- and yellow-light illumination, a computer-controlled custom LED ring surrounding the camera lens was positioned at a fixed distance above the swimming chamber (Supplementary Fig. 7d). The incident angle of the LEDs allowed for homogeneous illumination of the chamber's inner compartment. Each squared pulse of light of varying duration consisted of $100 \mathrm{~ms}$ flashes delivered at $5 \mathrm{~Hz}$. Light power was measured through a hand-held light power meter (Newport Corp, Irvine, CA, USA). All experiments involved single larvae, which moved freely within the chamber and were given an initial time period of $10 \mathrm{~min}$ to adapt to the chamber's conditions before tests.

Stressors. Groups of thirty larvae in $30 \mathrm{~mm}$ Petri dishes were exposed to three different protocols based on either blue or yellow light, $\mathrm{NaCl}$ or strong hydrodynamic flows and used for cortisol measurement or transferred to the custom-made swimming chamber for behavioural testing. Blue or yellow light: dark-adapted larvae were exposed to a $180 \mathrm{~s}$ squared pulse of either blue or yellow light as described above. Light power, $2.8 \mathrm{~mW} \mathrm{~cm}^{-2}$. NaCl: larvae were incubated for $10 \mathrm{~min}$ in steady-state $\mathrm{E} 2+50 \mathrm{mM} \mathrm{NaCl}\left(\mathrm{NaCl}_{50 \mathrm{mM}}\right.$, Merck, \#106404) medium at $28^{\circ} \mathrm{C}$ under white-light illumination. They were then washed three times with E2 medium. Strong hydrodynamic flows: larvae were presented with strong flows caused by rapid $1 \mathrm{~mm}$ lateral displacements of the end of a rigid silica capillary tube fixed to a multilayer piezo bender actuator (input voltage: $6 \mathrm{~V}$ ), as described elsewhere ${ }^{33}$. The end of the capillary was submerged $2 \mathrm{~mm}$ into the medium at the centre of a $35 \mathrm{~mm}$ Petri dish half filled $(1.8 \mathrm{ml})$ with E2 medium (orientation relative to water surface: $90^{\circ}$ ). Larvae were exposed to 6 stimulation units delivered with an inter-stimulation-interval of $250 \mathrm{~ms}$. Each unit consisted of 99 repetitions of $40 \mathrm{~ms}$ lateral displacements. Stimulations were carried out at $28^{\circ} \mathrm{C}$ under white illumination.

Whole-body cortisol. Groups of thirty larvae were immobilized in ice water $120 \mathrm{~s}$ after exposure to light, $\mathrm{NaCl}$ or strong flows. Control samples were collected after equal handling, omitting stressor exposure. Samples were then frozen in an ethanol/dry-ice bath and stored at $-20^{\circ} \mathrm{C}$ for subsequent extraction. Cortisol extraction and detection were carried out using a home-made cortisol ELISA protocol, as described elsewhere ${ }^{68}$

Recordings. Before recordings, single larvae were kept inside the chamber swimming in E2 medium at $28^{\circ} \mathrm{C}\left( \pm 0.1{ }^{\circ} \mathrm{C}\right)$ under infrared light for $10 \mathrm{~min}$. They were then exposed to either blue or yellow light, rising temperature or local WMs and their behaviour was video-recorded as described above.

Light avoidance. One half of the swimming chamber was covered with a single layer of long-pass filter foil. The resulting light power in the filtered chamber-half was reduced to $0.007-0.012 \%$ at $488 \mathrm{~nm}$ and $0.003-0.007 \%$ at $570 \mathrm{~nm}$, relative to the unfiltered half $\left(2.8 \mathrm{~mW} \mathrm{~cm}^{-2}\right)$, as measured with a light power meter (see above). Groups of five larvae were video-recorded while swimming freely for $3 \mathrm{~min}$ under infrared illumination only, and then presented with a $120 \mathrm{~s}$ pulse of either blue or yellow light. Incidences of a larva entering the illuminated side of the chamber were manually scored for timing and duration. Frequency and cumulative time spent in light were calculated over the course of the $120 \mathrm{~s}$ light phase for each larva.

Definition and scoring of 'cloak' and 'escape'. Cloak was defined as a tilted position of the body axis with the head facing up towards the LED ring and the body touching the walls of the chamber, that is, negative geotaxis plus thigmotaxis. Escape reactions were defined as fast swimming bouts along the chamber's wall at speeds that defied valid EthoVision XT 7 tracking because the larva was invisible in multiple subsequent videos frames (frame rate: $100 \mathrm{~Hz}$ ). The end of an escape bout was defined as the first frame in which the larva had slowed down to traceable speed or halted motion entirely. Occurrence, latency and duration of cloak and escape were scored manually for individual larvae during the entire $120 \mathrm{~s}$ of either blue or yellow light in each video.

Rising temperature. Single larvae were video-recorded for $240 \mathrm{~s}$ with the temperature of the flowing medium kept at $28^{\circ} \mathrm{C}\left( \pm 0.1^{\circ} \mathrm{C}\right)$. The input of the temperature control system was then stepped up by $10^{\circ} \mathrm{C}$, causing the temperature of the flowing medium to reach $34^{\circ} \mathrm{C}$ after $120 \mathrm{~s}$. The rising temperature produced a temperature difference between the inlet and outlet, zones 1 (high temperature) and 2 (low temperature), respectively, which reached its maximum 60-90 s after the onset of temperature increase (300-330 s of the whole recording session), a time window used to measure 'differential speed'.

Local WMs. Single larvae in the swimming chamber were video-recorded for $120 \mathrm{~s}$ under infrared light and constant temperature. Next, they were presented with $1 \mathrm{~ms}$ lateral displacements of the silica capillary tube delivered at $1 \mathrm{~Hz}$ (input voltage: $0.5 \mathrm{~V})$ for $120 \mathrm{~s}$, as described elsewhere ${ }^{35}$. Motion before and during stimulation was calculated using the integrals of motion over $120 \mathrm{~s}$.
Bioluminescence. Coelentrazine (CLNZ; Synchem, \#s053) was prepared as a $10 \mathrm{mM}$ stock solution in (2-Hydroxypropyl)- $\beta$-cyclodextrin (Tocris, \#0708) with $11.25 \%$ propylene glycol (Sigma-Aldrich, \#398039). The stock solution was diluted to a final working concentration of $40 \mu \mathrm{M}$ CLNZ in E3 medium. On the evening of 3 d.p.f., bPAC ${ }^{+} / \mathrm{GFP}^{-A e q u o r i n}{ }^{+}$and $\mathrm{bPAC}^{-} / \mathrm{GFP}^{-A e q u o r i n}{ }^{+}$larvae were dark-incubated in CLNZ solution at $25^{\circ} \mathrm{C}$; the CLNZ solution was replaced with a freshly diluted stock every $24 \mathrm{~h}$. At 6 d.p.f., they were washed four times in E3 medium and transferred in groups of 7 into a swimming chamber similar to that shown in Supplementary Fig. 7b (with neither in nor outlet) filled with E3 medium only. The chamber remained below the LED ring (as shown in Supplementary Fig. 7d) with its transparent glass bottom fixed $1.5 \mathrm{~mm}$ above a photomultiplier tube (Hamamatsu Photonics K.K., Shizuoka, Japan) covered with a custom-made TTL-controlled shutter and mounted inside a light-proof enclosure placed on a vibration-free platform. The shutter remained closed at all times until bioluminescence was measured. CLNZ-incubated larvae were first allowed to swim freely for $240 \mathrm{~s}$ and then exposed to a $120 \mathrm{~s}$ square pulse of either blue or yellow light $\left(100 \mathrm{~ms}\right.$ flashes delivered at $5 \mathrm{~Hz}$, light power: $\left.2.8 \mathrm{~mW} \mathrm{~cm}^{-2}\right)$. Photo-emission was measured with the photomultiplier tube at $1 \mathrm{~Hz}$ for $60 \mathrm{~s}$ immediately after the light offset.

Statistics. All data are shown as single measurement points or mean and standard error of the mean. We used a random experimental design, Spearman's rank correlations, Student's $t$-tests (two-tailed) for two-group comparisons, one-sample $t$-tests, G-tests and ANOVAs for multiple group comparisons (followed by Bonferroni's post hoc tests), or their non-parametric equivalents. Normality was tested using Kolmogorov-Smirnov, Shapiro-Wilk and D’Agostino tests. Analyses were made with EthoVision XT 7 (Noldus Information Technology), Matlab 2009b (MathWorks, Inc, Natick, MA; USA), MS-Excel (Microsoft Corp; Redmond, WA USA), Prism 5 (Graphpad Software Inc, San Diego, CA, USA), Sigma Plot (Systat Software Inc, San Jose, CA, USA), ImageJ (Freeware) and VirtualDub (Freeware)

Data availability. The data that support the findings of this study are available from the corresponding authors on request.

\section{References}

1. Selye, H. Endocrine reactions during stress. Curr. Res. Anesth. Analg. 35, 182-193 (1956).

2. Chrousos, G. P. Stressors, stress and neuroendocrine integration of the adaptive response. The 1997 Hans Selye memorial lecture. Ann. N. Y. Acad. Sci. 851, 311-335 (1998).

3. Harris, G. W. The function of the pituitary stalk. Bull. Johns Hopkins Hosp. 97, 358-375 (1955).

4. Knigge, K. M. \& Scott, D. E. Structure and function of the median eminence Am. J. Anat. 129, 223-243 (1970).

5. Charmandari, E., Tsigos, C. \& Chrousos, G. Endocrinology of the stress response. Annu. Rev. Physiol. 67, 259-284 (2005).

6. Aguilera, G., Nikodemova, M., Wynn, P. C. \& Catt, K. J. Corticotropin releasing hormone receptors: two decades later. Peptides 25, 319-329 (2004).

7. Luini, A., Lewis, D., Guild, S., Corda, D. \& Axelrod, J. Hormone secretagogues increase cytosolic calcium by increasing cAMP in corticotropin-secreting cells. Proc. Natl Acad. Sci. USA 82, 8034-8038 (1985).

8. Hermans, E. J., Henckens, M. J., Joëls, M. \& Fernández, G. Dynamic adaptation of large-scale brain networks in response to acute stressors. Trends Neurosci. 37, 304-314 (2014).

9. Koob, G. F. The behavioral neuroendocrinology of corticotropin-releasing factor, growth hormone-releasing factor, somatostatin and gonadotropinreleasing hormone. in Neuroendocrinology. (ed. Nemeroff, C. B.) 353-364 (CRC Press, 1992).

10. Lowry, C. A. \& Moore, F. L. Regulation of behavioral responses by corticotropin-releasing factor. Gen. Comp. Endocrinol. 146, 19-27 (2006).

11. Groeneweg, F. L., Karst, H., de Kloet, E. R. \& Joëls, M. Rapid non-genomic effects of corticosteroids and their role in the central stress response. J. Endocrinol. 209, 153-167 (2011).

12. Tasker, J. G., Di, S. \& Malcher-Lopes, R. Minireview: rapid glucocorticoid signaling via membrane-associated receptors. Endocrinology 147, 5549-5556 (2006).

13. Joëls, M., Sarabdjitsingh, R. A. \& Karst, H. Unraveling the time domains of corticosteroid hormone influences on brain activity: rapid, slow, and chronic modes. Pharmacol. Rev. 64, 901-938 (2012).

14. Karst, H. et al. Mineralocorticoid receptors are indispensable for nongenomic modulation of hippocampal glutamate transmission by corticosterone. Proc Natl Acad. Sci. USA 102, 19204-19207 (2005).

15. Olijslagers, J. E. et al. Rapid changes in hippocampal CA1 pyramidal cell function via pre- as well as postsynaptic membrane mineralocorticoid receptors. Eur. J. Neurosci. 27, 2542-2550 (2008).

16. Karst, H., Berger, S., Erdmann, G., Schütz, G. \& Joëls, M. Metaplasticity of amygdalar responses to the stress hormone corticosterone. Proc. Natl Acad. Sci. USA 107, 14449-14454 (2010) 
17. Di, S., Malcher-Lopes, R., Halmos, K. C. \& Tasker, J. G. Nongenomic glucocorticoid inhibition via endocannabinoid release in the hypothalamus: a fast feedback mechanism. J. Neurosci. 23, 4850-4857 (2003).

18. Di, S., Malcher-Lopes, R., Marcheselli, V. L., Bazan, N. G. \& Tasker, J. G. Rapid glucocorticoid-mediated endocannabinoid release and opposing regulation of glutamate and gamma-aminobutyric acid inputs to hypothalamic magnocellular neurons. Endocrinology 146, 4292-4301 (2005).

19. Di, S., Maxson, M. M., Franco, A. \& Tasker, J. G. Glucocorticoids regulate glutamate and GABA synapse-specific retrograde transmission via divergent nongenomic signaling pathways. J. Neurosci. 29, 393-401 (2009).

20. Greven, H. M. \& de Wied, D. The influence of peptides derived from corticotrophin (ACTH) on performance. Structure activity studies. Prog. Brain Res. 39, 429-442 (1973).

21. de Wied, D. \& Jolles, J. Neuropeptides derived from pro-opiocortin: behavioral, physiological, and neurochemical effects. Physiol. Rev. 62, 976-1059 (1982).

22. Sandi, C., Venero, C. \& Guaza, C. Novelty-related rapid locomotor effects of corticosterone in rats. Eur. J. Neurosci. 8, 794-800 (1996).

23. Rose, J. D., Marrs, G. S. \& Moore, F. L. Rapid, corticosterone-induced disruption of medullary sensorimotor integration related to suppression of amplectic clasping in behaving roughskin newts (Taricha granulosa). Horm. Behav. 34, 268-282 (1998).

24. Mikics, E., Barsy, B., Barsvári, B. \& Haller, J. Behavioral specificity of non-genomic glucocorticoid effects in rats: effects on risk assessment in the elevated plus-maze and the open-field. Horm. Behav. 48, 152-162 (2005).

25. Wendelaar Bonga, S. E. The stress response in fish. Physiol. Rev. 77, 591-625 (1997).

26. Ryu, M. H., Moskvin, O. V., Siltberg-Liberles, J. \& Gomelsky, M. Natural and engineered photoactivated nucleotidyl cyclases for optogenetic applications. J. Biol. Chem. 285, 41501-41508 (2010).

27. Stierl, M. et al. Light modulation of cellular cAMP by a small bacterial photoactivated adenylyl cyclase, bPAC, of the soil bacterium Beggiatoa. J. Biol. Chem. 286, 1181-1188 (2011).

28. De Marco, R. J., Groneberg, A. H., Yeh, C. M., Castillo Ramírez, L. A. \& Ryu, S. Optogenetic elevation of endogenous glucocorticoid level in larval zebrafish. Front. Neural Circuits 7, 82 (2013).

29. Liu, N. A. et al. Pituitary corticotroph ontogeny and regulation in transgenic zebrafish. Mol. Endocrinol. 17, 959-966 (2003).

30. Tse, A., Lee, A. K. \& Tse, F. W. $\mathrm{Ca}^{2+}$ signaling and exocytosis in pituitary corticotropes. Cell Calcium 51, 253-259 (2012).

31. Baubet, V. et al. Chimeric green fluorescent protein-aequorin as bioluminescent $\mathrm{Ca}^{2+}$ reporters at the single-cell level. Proc. Natl Acad. Sci. USA 97, 7260-7265 (2000).

32. Agulleiro, M. J. et al. Role of melanocortin receptor accessory proteins in the function of zebrafish melanocortin receptor type 2. Mol. Cell. Endocrinol. 320, 145-152 (2010).

33. De Marco, R. J., Groneberg, A. H., Yeh, C. M., Treviño, M. \& Ryu, S. The behavior of larval zebrafish reveals stressor-mediated anorexia during early vertebrate development. Front. Behav. Neurosci. 8, 367 (2014).

34. Kalmijn, A. J. in Sensory Biology of Aquatic Animals (eds Atema, J., Fay, R. R., Popper, A. N. \& Tavolga, W. N.) 83-130 (Springer, 1988).

35. Groneberg, A. H., Herget, U., Ryu, S. \& De Marco, R. J. Positive taxis and sustained responsiveness to water motions in larval zebrafish. Front. Neural Circuits 9, 9 (2015).

36. Herget, U., Wolf, A., Wullimann, M. F. \& Ryu, S. Molecular neuroanatomy and chemoarchitecture of the neurosecretory preoptic-hypothalamic area in zebrafish larvae. J. Comp. Neurol. 522, 1542-1564 (2014).

37. Alsop, D. \& Vijayan, M. M. Development of the corticosteroid stress axis and receptor expression in zebrafish. Am. J. Physiol. Regul. Integr. Comp. Physiol. 294, R711-R719 (2008).

38. Alsop, D. \& Vijayan, M. M. Molecular programming of the corticosteroid stress axis during zebrafish development. Comp. Biochem. Physiol. A Mol. Integr. Physiol. 153, 49-54 (2009).

39. Alderman, S. L. \& Bernier, N. J. Ontogeny of the corticotropin-releasing factor system in zebrafish. Gen. Comp. Endocrinol. 164, 61-69 (2009).

40. Mirsky, I. A., Miller, R. \& Stein, M. Relation of adrenocortical activity and adaptive behavior. Psychosom. Med. 15, 584-584 (1953).

41. Murphy, J. V. \& Miller, R. E. The effect of adrenocorticotrophic hormone (ACTH) on avoidance conditioning in the rat. J. Comp. Physiol. Psychol. 48, 47-49 (1955).

42. Ferrari, W. Behavioural changes in animals after intracisternal injection with adrenocorticotrophic hormone and melanocyte-stimulating hormone. Nature 181, 925-926 (1958).

43. Gispen, W. H., Wiegant, V. M., Greven, H. M. \& de Wied, D. The induction of excessive grooming in the rat by intraventricular application of peptides derived from ACTH: structure-activity studies. Life Sci. 17, 645-652 (1975).

44. Bohus, B., Hendrickx, H. H. L., Van Kolfschoten, A. A. \& Krediet, T. G. Effect of ACTH 4-10 on copulatory and sexually motivated approach behavior in the male rat. in Sexual Behavior: Pharmacology and Biochemistry. (eds Sandler, M. \& Gessa, G. L.) 269-275 (Raven Press, 1975).
45. de Wied, D. Behavioral effects of neuropeptides related to ACTH, MSH, and betaLPH. Ann. N. Y. Acad. Sci. 297, 263-274 (1977).

46. Breuner, C. W., Greenberg, A. L. \& Wingfield, J. C. Noninvasive corticosterone treatment rapidly increases activity in Gambel's white-crowned sparrows (Zonotrichia leucophrys gambelii). Gen. Comp. Endocrinol. 111, 386-394 (1998).

47. Hayden-Hixson, D. M. \& Ferris, C. F. Steroid-specific regulation of agonistic responding in the anterior hypothalamus of male hamsters. Physiol. Behav. 50, 793-799 (1991).

48. Hayden-Hixson, D. M. \& Ferris, C. F. Cortisol exerts site-, context- and dosedependent effects on agonistic responding in hamsters. J. Neuroendocrinol. 3, 613-622 (1991).

49. Haller, J., Albert, I. \& Makara, G. B. Acute behavioural effects of corticosterone lack specificity but show marked context-dependency. J. Neuroendocrinol. 9, 515-518 (1997).

50. Moore, F. L. \& Miller, L. J. Stress-induced inhibition of sexual behavior: corticosterone inhibits courtship behaviors of a male amphibian (Taricha granulosa). Horm. Behav. 18, 400-410 (1984).

51. Kubli-Garfias, C. Chemical structure of corticosteroids and its relationship with their acute induction of lordosis in the female rat. Horm. Behav. 24, 443-449 (1990).

52. Bicknell, A. B. The tissue-specific processing of pro-opiomelanocortin. J. Neuroendocrinol. 20, 692-699 (2008).

53. Mezey, E., Palkovits, M., de Kloet, E. R., Verhoef, J. \& de Wied, D. Evidence for pituitary-brain transport of a behaviorally potent ACTH analog. Life Sci. 22, 831-838 (1978).

54. Cerdá-Reverter, J. M. et al. Fish melanocortin system. Eur. J. Pharmacol. 660, 53-60 (2011).

55. Stene, M. et al. Plasma norepinephrine levels are influenced by sodium intake, glucocorticoid administration, and circadian changes in normal man. J. Clin. Endocrinol. Metab. 51, 1340-1345 (1980).

56. Valenta, L. J., Elias, A. N. \& Eisenberg, H. ACTH stimulation of adrenal epinephrine and norepinephrine release. Horm. Res. 23, 16-20 (1986).

57. Liston, C. et al. Circadian glucocorticoid oscillations promote learning-dependent synapse formation and maintenance. Nat. Neurosci. 16, 698-705 (2013).

58. Stavreva, D. A. et al. Ultradian hormone stimulation induces glucocorticoid receptor-mediated pulses of gene transcription. Nat. Cell Biol. 11, 1093-1102 (2009).

59. Groeneweg, F. L., Karst, H., de Kloet, E. R. \& Joëls, M. Mineralocorticoid and glucocorticoid receptors at the neuronal membrane, regulators of nongenomic corticosteroid signalling. Mol. Cell. Endocrinol. 350, 299-309 (2012).

60. Joëls, M., Pasricha, N. \& Karst, H. The interplay between rapid and slow corticosteroid actions in brain. Eur. J. Pharmacol. 719, 44-52 (2013).

61. Gutierrez-Triana, J. A., Herget, U., Lichtner, P., Castillo-Ramírez, L. A. \& Ryu, S. A vertebrate-conserved cis-regulatory module for targeted expression in the main hypothalamic regulatory region for the stress response. BMC Dev. Biol. 14, 41 (2014).

62. Gutierrez-Triana, J. A. et al. Manipulation of interrenal cell function in developing zebrafish using genetically targeted ablation and an optogenetic tool. Endocrinology 156, 3394-3401 (2015).

63. Westerfield, M. The Zebrafish Book. A Guide for the Laboratory Use of Zebrafish (Danio rerio) 4th edn (University of Oregon Press, 2000).

64. To, T. T. et al. Pituitary-interrenal interaction in zebrafish interrenal organ development. Mol. Endocrinol. 21, 472-485 (2007).

65. Lauter, G., Söll, I. \& Hauptmann, G. Multicolor fluorescent in situ hybridization to define abutting and overlapping gene expression in the embryonic zebrafish brain. Neural Dev. 6, 10 (2011).

66. Kastenhuber, E., Kratochwil, C. F., Ryu, S., Schweitzer, J. \& Driever, W. Genetic dissection of dopaminergic and noradrenergic contributions to catecholaminergic tracts in early larval zebrafish. J. Comp. Neurol. 518, 439-458 (2010).

67. Ryu, S. et al. Orthopedia homeodomain protein is essential for diencephalic dopaminergic neuron development. Curr. Biol. 17, 873-880 (2007).

68. Yeh, C. M., Glöck, M. \& Ryu, S. An optimized whole-body cortisol quantification method for assessing stress levels in larval zebrafish. PLoS ONE 8, e79406 (2013).

\section{Acknowledgements}

We thank L. Castillo-Ramírez and C.-M. Yeh for assistance with the experiments, A. Gutierrez-Triana for the $m c 2 r$ probe, G. Shoeman, R. Singer and A. Schoell for expert fish care, K. Schmidt, R. Rödel, M. Lukat and N. Neef for technical support, and M. Gil and C. Lafourcade for suggestions. This work was supported by DFG-FOR1279, the Max Planck Society and Behrens-Weise Foundation.

\section{Author contributions}

R.J.D.M. and S.R. conceived the research. R.J.D.M. designed the experiments and oversaw the project. S.R. generated the transgenic line. R.J.D.M., T.T., A.H.G. and 
U.H. performed the experiments. R.J.D.M. analysed the data with assistance of T.T. and A.H.G. R.J.D.M. and S.R. wrote the paper with the assistance of T.T. and U.H.

\section{Additional information}

Supplementary Information accompanies this paper at http://www.nature.com/ naturecommunications

Competing financial interests: R.J.D.M. and S.R. are authors of the EP Patent application 1380 2343.7, 'Novel inducible animal model of stress behavior.'

The remaining authors declare no competing financial interests.

Reprints and permission information is available online at http://npg.nature.com/ reprintsandpermissions/
How to cite this article: De Marco, R. J. et al. Optogenetically enhanced pituitary corticotroph cell activity post-stress onset causes rapid organizing effects on behaviour. Nat. Commun. 7:12620 doi: 10.1038/ncomms12620 (2016).

(c) (i) This work is licensed under a Creative Commons Attribution 4.0 International License. The images or other third party material in this article are included in the article's Creative Commons license, unless indicated otherwise in the credit line; if the material is not included under the Creative Commons license, users will need to obtain permission from the license holder to reproduce the material. To view a copy of this license, visit http://creativecommons.org/licenses/by/4.0/

(C) The Author(s) 2016 